\title{
(6) OPEN ACCESS \\ Beliefs and experiences can influence patient participation in handover between primary and secondary care-a qualitative study of patient perspectives
}

\author{
Maria Flink, ${ }^{1,2}$ Gunnar Öhlén, ${ }^{3,4}$ Helen Hansagi, ${ }^{5}$ Paul Barach, ${ }^{6,7}$ Mariann Olsson ${ }^{1,2}$
}

\author{
${ }^{1}$ Department of \\ Neurobiology, Care Sciences \\ and Society, Division of \\ Social Work, Karolinska \\ Institutet, Stockholm, \\ Sweden \\ ${ }^{2}$ Department of Social Work, \\ Karolinska University \\ Hospital, Stockholm, \\ Sweden \\ ${ }^{3}$ Department of Clinical \\ Science, Intervention and \\ Technology, Karolinska \\ Institutet, Stockholm, \\ Sweden \\ ${ }^{4}$ Department of Quality and \\ Patient Safety, Karolinska \\ University Hospital, \\ Stockholm, Sweden \\ ${ }^{5}$ Department of Clinical \\ Neuroscience, Division of \\ Psychiatric Research and \\ Education, Karolinska \\ Institutet, Stockholm, \\ Sweden \\ ${ }^{6}$ Center for Patient Safety, \\ Department of Anesthesia, \\ Utrecht University Medical \\ Center, Utrecht, Netherlands \\ ${ }^{7}$ Department of Health \\ Studies, University of \\ Stavanger, Stavanger, \\ Norway
}

Correspondence to Maria Flink, Department of Neurobiology, Care Sciences and Society, Division of Social Work, Karolinska University Hospital, Kuratorskliniken B44, Huddinge, S-14186 Stockholm, Sweden; maria. flink@ki.se

Accepted 22 August 2012 Published Online First 29 October 2012

\section{ABSTRACT}

Background: Communication between healthcare settings at patient transfers between primary and secondary care, 'handover', is a critical and risky process for patients. Patients' views on their roles in these processes are often lacking despite the knowledge that patient participation contributes to enhanced safety and wellbeing.

Objective: This study aims to improve the knowledge and understanding of patients' perspectives about their participation in handover.

Methods: Twenty-three Swedish patients with chronic diseases were individually interviewed about their experiences with handovers between three clinical microsystems: emergency room, emergency ward and primary healthcare centres. Data were analysed using inductive qualitative content analysis.

Results: Patients participated within the microsystems by exchanging information, and between microsystems by making contact with and conveying information to their next healthcare provider. Enablers for participation included positive encounters with providers, patient empowerment and beliefs about organisational factors. Patients' trust in their providers, and providers' attitudes were important factors in patients' willingness to communicate. Patients who thought medical records access was shared across microsystems volunteered less information to their providers. Patients with experiences of non-effective handovers took more responsibility in the handover to ensure continuity of care.

Conclusions: Patients participate actively in handovers when they feel a need for involvement to ensure continuity of care, and are less active when they perceive that their contribution is unnecessary or not valued. In acute care settings with short hospital stays and less time to establish a trusting relationship between patients and their providers, discharge encounters may be important enablers for patient engagement in handovers. The advantages of a redundant handover process need to be considered.

\section{INTRODUCTION}

Handover communication, including the exchange of information and transfer of responsibility between hospitals and primary care providers, is crucial for ensuring safe patient transfers between these care settings. Patients receive care in several different clinical microsystems as they move from ambulatory care to an inpatient hospitalisation, and back to their primary care microsystem. ${ }^{1}$ Poor coordination of patient care and communication failures across these systems can compromise patient safety. ${ }^{2-5}$ For example, adverse events occur in up to $49 \%$ of patient discharges from the hospital, ${ }^{2}{ }^{6}$ and $67 \%$ of patients experience at least one adverse drug event during hospital admissions. ${ }^{78}$

Patient participation in handover communication has been suggested to improve the outcome of handovers. ${ }^{8-11}$ Interventions that engage patients as active participants result in safer handovers and lower rehospitalisation rates. ${ }^{12} 13$ To date patient participation in handovers has mostly been studied for hospital discharges, and has not included handovers between the community and primary healthcare setting and the hospital. Efforts to improving patient handovers benefit from understanding how patients view their participation in the handover process, and, the prerequisites for that participation. Previous studies have found that patient views on healthcare depend on national culture, ${ }^{14}$ thus requiring international and countryspecific studies. This study aims to improve the knowledge and understanding of patients' perspectives, using Swedish patients as exemplars, about their participation in 
handover communication between primary and secondary care at the time of hospital admission and at discharge. A further objective was to suggest guidance for clinical training and reflection on the role and empowerment of patients.

\section{METHODS}

Our study was conducted as part of the European HANDOVER Project, multi-nation initiative to improve handovers at the hospital to primary healthcare interface. ${ }^{15}$ Participating nations involved The Netherlands, Spain, Poland, Italy and Sweden, which collectively represent a varying European healthcare and funding systems. In the Swedish healthcare system patients are able to choose their healthcare provider; ${ }^{16}$ in addition national legislation regarding patient participation recently has been strengthened. ${ }^{17}$ When Swedish patients need emergency care, they are encouraged but not required to consult with their general practitioner. They are free to seek care at any emergency room (ER) in any hospital. ${ }^{16}$ Sweden's National Board of Health and Welfare stipulates that information must be transferred between the involved clinical microsystems by the time of hospital admission and discharge. ${ }^{18}$

The focus of our study is the Swedish patients' perspectives on their participation in handovers at two instances of their care: during their transition from primary care to hospital via the ER, and back to the primary care for medical follow-up (see figure 1).

\section{Settings}

The clinical systems in the study included one ER and four emergency wards at a university hospital in Stockholm, Sweden, and 18 primary healthcare centres, including one nursing home. The ER receives approximately 86000 visits a year, with an admission rate of $25 \%$. The four emergency wards have 71 beds and an average patient stay of $48 \mathrm{~h}$. All settings have access to electronic medical records. While most primary

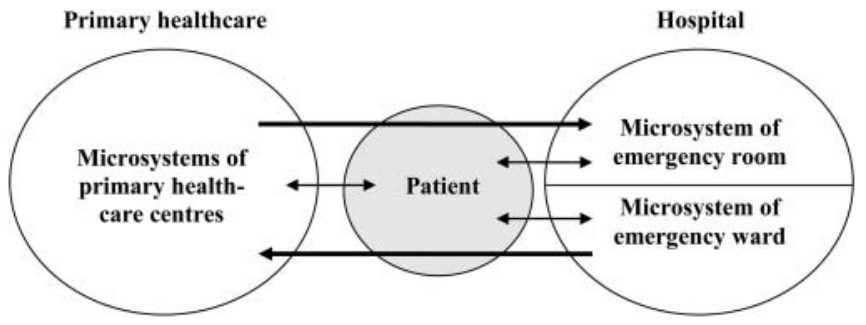

Figure 1 Illustration of the handover processes. The short double-arrows represent patients' participation within the involved clinical microsystems and the longer arrows represent patient participation in handover processes between the microsystems. healthcare centres in the study had access to the hospital's medical records, inpatient, medical records for hospitalised patients could be accessed only from a few of the primary healthcare centres.

\section{Participants}

Study participants included chronically ill patients, who presented to the ER due to an acute condition or an exacerbation in their chronic condition, and who were subsequently hospitalised in an emergency ward. Patients with chronic diseases were chosen because of their need for frequent care and continuity of care, and the likelihood of experience with multiple handovers. The inclusion criteria were: hospitalised patients from 18 years and upwards who were discharged home or to a nursing home implying primary or community care, and with any of the diagnoses-diabetes mellitus, chronic obstructive pulmonary disease, heart failure, asthma and/or polypharmacy, defined as six or more prescribed drugs. We excluded patients with severe psychiatric condition, limited knowledge of the Swedish language and patients discharged to another country.

We estimated that 20-25 patients needed to be recruited to get broad perspectives of younger and older, female and male patients with different chronic conditions and used purposive sampling ${ }^{19}$ to gather information from patients of different ages, gender and the included diagnostic groups. Of the 266 patients who met the inclusion criteria, we identified 34 patients who were asked to participate. Of these, 32 patients accepted and 23 patients were interviewed. The reasons for subject dropout included patients who were too sick to participate $(n=2)$, died before the interview $(n=3)$, or changed their mind about participation $(n=4)$.

Participants ranged in age from 41 to 84 years old, with a mean age of 67 years. The distribution of sampling characteristics is shown in table 1 . Fifteen patients co-habited and eight lived alone. Of the ten patients of working age $(<65$ years old), four were working, and the others were on sick leave or disability pension. One patient was homeless.

\section{Procedures}

For patients meeting the inclusion criterion the day of discharge from the index hospitalisation, a project nurse met with them and informed them about the project. Patients who agreed to participate were sent an information letter 1-2 weeks after discharge, and were called thereafter to schedule the interview.

The interviews used a semi-structured interview guide, developed by the European HANDOVER Research Collaborative, ${ }^{20}$ and pilot tested for this purpose (the interview guide is available upon request). The interview 
Table 1 Patient diagnosis and length of index hospital stay

\begin{tabular}{|c|c|c|c|c|}
\hline & \multicolumn{2}{|c|}{ Male $(n=12)$} & \multicolumn{2}{|c|}{ Female $(n=11)$} \\
\hline & $<65$ years & $\geq 65$ years & $<65$ years & $\geq 65$ years \\
\hline \multicolumn{5}{|l|}{ Diagnostic group } \\
\hline Diabetes mellitus & 3 & 1 & 1 & 1 \\
\hline COPD & 0 & 2 & 2 & 3 \\
\hline Heart failure & 2 & 1 & 0 & 3 \\
\hline Asthma & 1 & 1 & 1 & 0 \\
\hline Polypharmacy* & 0 & 1 & 0 & 0 \\
\hline \multicolumn{5}{|l|}{ Length of index hospital stay } \\
\hline Number of days, mean (range) & $2.8(2-3)$ & $3(1-7)$ & $3(1-5)$ & $2.4(1-5)$ \\
\hline
\end{tabular}

guide allowed for prompts and follow-up questions. For the present study, only the sections that asked about patients' participation in the handover were used.

The interviews were performed in person 1-7 weeks after discharge (on average 4.4 weeks), allowing time for a follow-up by the primary healthcare provider. Interviews occurred in patients' homes or, if the patient preferred, at the hospital-sometimes with a family member present. The two female interviewers were a registered nurse (FA) and a medical social worker (MF). Both had experience working with emergency care patients and neither was involved in the treatment of the patients in the study. The interviews lasted between 20 and $90 \mathrm{~min}$. They were audio-taped and transcribed verbatim.

Patients gave informed consent to participate in the study after they had received both oral and written information about the project. This included the assurance that they could withdraw their consent at any time without any consequences. The study was approved by the regional ethical review board in Stockholm, Sweden (No. 2008/1933-31/2).

\section{Data analysis}

The data were structured using the software ATLAS.ti, V.6, ${ }^{21}$ and analysed using qualitative conventional content analysis. ${ }^{22}$ The interviews were read word by word and then coded inductively by two authors (MF and MO). The data were extracted from quotes about participation in handovers, and all communication between patient and care provider concerning patients' previous and present health condition and planned future care was regarded as handover communication (see table 2). Coding involved extensive discussion among the authors and, where necessary, new codes were added and previously analysed interviews were recoded. Codes were categorised into nine categories and 16 subcategories; themes and subthemes based on the categories were elaborated (table 3).

We sought to reach a comprehensive understanding of patient participation throughout the handover process. Finally, we mapped the codes to detect possible differentiation between the various clinical microsystems where the handover communication occurred. The results section findings are structured according to the discreet steps in the handover process (see figure 1).

\section{RESULTS}

The analysis resulted in two main themes: 'Experience of participation' and 'Enablers for participation' in handover communication (table 3). The experiences of participation included exchanging information with the healthcare providers within and between the clinical microsystems and examples of passive or active participation. The enablers for participation included the encounters between patients and healthcare providers, patient-related and organisational factors. In general,

Table 2 Example of coding procedure

\begin{tabular}{|c|c|c|c|}
\hline Quotes about handover & Code & Subcategory & Category \\
\hline $\begin{array}{l}\text { 'And if I wonder about something ... l'm that kind of person who } \\
\text { dares to speak up and ask, so that makes it easier for me than for } \\
\text { others.' }\end{array}$ & $\begin{array}{l}\text { Personality gives } \\
\text { advantage }\end{array}$ & $\begin{array}{l}\text { Patients' } \\
\text { resources }\end{array}$ & $\begin{array}{l}\text { Patient } \\
\text { empowerment }\end{array}$ \\
\hline $\begin{array}{l}\text { "I usually say to the discharging doctor "Please send this to the } \\
\text { primary healthcare centre and to my private doctor." }\end{array}$ & $\begin{array}{l}\text { Asking for } \\
\text { handover }\end{array}$ & Patient activity & $\begin{array}{l}\text { Actively } \\
\text { participating }\end{array}$ \\
\hline
\end{tabular}


Table 3 Results of the analysis-categories, subthemes and themes

\begin{tabular}{|c|c|c|}
\hline Category & Subtheme & Theme \\
\hline 1. Exchanging information & 1. Exchanging information & \multirow[t]{3}{*}{ A. Experience of participation } \\
\hline 2. Not actively participating & 2. Own activity & \\
\hline 3. Actively participating & & \\
\hline $\begin{array}{l}\text { 4. Meetings between patients and healthcare providers } \\
\text { 5. Healthcare providers attitude and empathy } \\
\text { 6. Feelings of trust }\end{array}$ & 3. Encounter-related factors & \multirow[t]{4}{*}{ B. Enablers for participation } \\
\hline 7. Patient empowerment & 4. Patient-related factors & \\
\hline 8. Patient preference & & \\
\hline 9. Beliefs and experiences about organisational aspects & 5. Organisational factors & \\
\hline
\end{tabular}

the patients did not differentiate between the different healthcare professions in their statements. All personnel, for example, nurses, physicians, physiotherapists, are presented as a group entitled the healthcare providers.

\section{Handover from primary healthcare to ER Experience of participation}

During handovers from the primary healthcare to the ER some patients participated by sharing information about present and previous acute conditions, and medication and interventions that had helped on previous occasions. Other interviewees indicated they perceived that healthcare providers did not facilitate patients' contribution to handover communication, asking few questions during the handover. Patients' interpreted this dearth of questions about information from them, other than regarding their current, acute condition, as not important or valued by their providers. A 64-year-old woman explained, The most important thing for the healthcare providers is the acute condition that they are to treat there and then'.

Patients also actively participated in the handover when bringing their medication list from home. 'And then I show them my medication list. I always have it with me, so they can see what medications I take'. (Man, 73 years) only three patients brought a written referral to the ER, even though several had consulted their primary healthcare provider or home-help service, and been advised to go to the hospital.

\section{Enablers for participation}

The attitude of the healthcare providers during the ER encounters was an important enabler for patients' willingness to participate in handovers. When patients perceived a positive attitude from the attending care provider they were more willing to communicate. Examples of positive attitudes included healthcare providers responding to the patients' handover information, indicating their understanding of the patient's situation and adjusting their communicated information to patients' needs and abilities. A 57-year-old man said, 'I have never experienced that they don't have time for my questions at the ER, even when they are stressed'. Also, when patients felt a negative or indifferent attitude it influenced their participation, such as when providers that did not act on or questioned patients' information, and, decisions that appeared to be made against explicit patients' wishes or without their knowledge. When the situation was perceived as stressful and time constrained, patients neither received nor gave as much information as they wanted or could have given.

Patients felt empowered to participate based on their own personality characteristics and previous healthcare experiences. However, the communication abilities of patients could be reduced due to their frail health condition. The patients used their family members to overcome this barrier of communicating with their healthcare providers. 'When I am too sick, my wife talks for me'. (Man, 51 years)

The patients' beliefs and experiences about the healthcare organisation influenced their participation. Patients who believed that the healthcare providers had all the necessary information in the medical records, either from previous admissions or from a shared medical record, limited the information they shared with their healthcare providers. A 64-year-old man said, 'What they need to know is already in my medical record, everything is in there'.

\section{Handover from emergency ward to primary healthcare Experience of participation}

During handovers from the emergency ward to the primary healthcare, patients perceived that little or no information was exchanged between the emergency ward and primary healthcare unless patients themselves conveyed it to ensure continuity of care. 'Yes, I always ask, 'I've been admitted to the hospital, did you get any message?' And then they look at their computer'. (Woman, 74 years) At their discharge patients specified which primary healthcare provider should receive their handover information, and actively took it upon 
themselves to ensure continuity of care between their healthcare providers. Active participation was present after discharge when patients contacted the primary healthcare centre on their own initiative to arrange a follow-up. A 77-year-old woman said, 'They have not contacted me from the primary healthcare centre, I do not like that. At the hospital they said that I should be contacted, but it was the other way around'. Patients' participation was also initiated by the healthcare providers who asked them to convey information to the primary healthcare about the discharge.

Other patients reported they had a more passive role, receiving information about care, treatment and handover arrangements and were content with this. These patients waited more passively for the primary healthcare providers to contact them for the medical follow-up.

\section{Enablers for participation}

Patients reported on a lack of formal handover encounters both on the emergency ward and in the primary healthcare settings. About one third of patients did not recall a formal discharge encounter with healthcare providers before leaving the hospital, and none mentioned experiencing a discharge planning conference. Nearly half of the patients did not mention a medical follow-up with their primary care provider after discharge. Clinical rounds during the hospital stay and formal discharge encounters were seen both as a facilitator and a barrier to patient communication. A positive bedside manner, including the healthcare providers sitting down by/on the bed and talking to the patient in a relaxed manner, was seen as a facilitator, while a large number of healthcare providers on rounds were viewed as a barrier. 'When the doctors are on their rounds, it's terrible. They come into the room, often with a lot of students, and then at first the doctor talks with the students for $15 \mathrm{~min}$, teaching them; well, but I want to have a word with the doctor! So, this really distracts you'. (Man, 68 years)

The trust of patients in their healthcare providers, and providers' past attitudes were important factors for patients' willingness to communicate. Patients wanted to communicate with personnel they knew and/or had good experiences in past dealing with. They would limit information shared with healthcare providers if they distrusted or felt uncomfortable with them. At times patients would wait to give or ask for information until a specific trusted person was available or had time for them. A 72 year-old man said, 'I have some specific persons at the primary healthcare centre that I know and that I talk to'.

Patients' interest in active participation also was guided by their past experiences, which taught them how to interact and communicate effectively with healthcare providers. A 62-year-old woman said, 'I'm that kind of person who is able to speak for myself and convey my needs'. Some patients indicated they had not given much thought to their participation in the handover process. These patients either trusted the handover system and the healthcare providers' performance or they did not consider participation in handovers a reasonable patient task.

The third enabling factor was patients' previous and present experiences with the organisation. The patients had learned from previous handovers that information was transferred through electronic communication between the hospital and the primary healthcare. These patients did not consider it necessary to participate in the handover communication between settings. A 71-year-old man said, 'They don't have to ask so much at the primary healthcare centre, they just look (at the computer) and see everything'. Another barrier was the lack of time. Two patients became so irritated over waiting for the healthcare providers that they left the hospital before the formal discharge encounter, 'They said: 'He is coming, he is coming, he is coming,' but nobody came and then I finally said: 'No, I'm going home now." (Man, 51 years)

\section{DISCUSSION}

The aim of this study was to improve our knowledge and understanding of patients' perspectives about participation in handover communication, and to suggest guidance for further training, reflection and policy development. The contribution of this qualitative study is to bring forward patients' perspectives, beliefs and attitudes, related to their participation in handovers between primary and secondary care. Patients participated by exchanging information related to the handover within and between the clinical microsystems involved in their care. Within the microsystem, they exchanged information with healthcare providers at the time of hospital admission, discharge and follow-up and specified which healthcare providers should receive the information; between microsystems, patients participated in handovers by conveying information such as medication lists and referral information, and by actively contacting their next care unit.

We found three groups of sub-themes that enabled participation: encounter-related, patient-related and organisational. Across all types of handovers, patients felt empowered to participate based on personal characteristics, and attitudes and empathy of the healthcare providers. Some of the enabling factors found in our study also have been identified in research on patient participation in their healthcare in general, including patient knowledge and ability, ${ }^{23-25}$ and healthcare providers' attitudes and responses to patient needs. ${ }^{23-25}$ 
Our findings suggest that participation of patients with chronic diseases is related to their beliefs, entrusting encounters, and their experiences during similar handovers in the past. Beliefs about a shared medical record or electronic transfer of records between clinical microsystems, along with a limited number of questions asked by the healthcare providers, can result in limited patient participation at hospital admission. While Ventres et al found that use of electronic medical records gave patients and healthcare providers a feeling of 'seamless communication' between different settings, ${ }^{26}$ our finding that these perceptions of seamlessness reduced patient participation is new, and was potentially fostered by the fact that most primary healthcare centres in the region had access privileges to the hospital's medical records. This misperception on the part of patients apparently was not addressed or corrected by the healthcare providers.

Patients' earlier experiences from handover communication also influenced their behaviour in the next handover. Patients who had experienced poor communication between clinical microsystems had gained motivation for active participation to compensate for these shortcomings. This is similar to the findings by Davis et al who reported that experiences of prior adverse events increased patient involvement in safety issues. ${ }^{23}$

Common suggestions for improving handovers by active patient participation include patients (a) bringing medication lists to hospital admission, ${ }^{7}$ (b) functioning as couriers between clinical microsystems, ${ }^{8}{ }^{11}$ (c) seeking instructions from healthcare providers by the time of discharge, ${ }^{10}$ and, (d) actively participating in organised discharge planning. ${ }^{9} 27-28$ In addition, several studies found reduced rehospitalisation rates when patients received feedback about their role during the handover and postdischarge care in organised sessions. ${ }^{12-13} 29$ During admission handovers, most Swedish patients shared medication lists, which has been shown effective in reducing medication errors. ${ }^{7}$ However, only three functioned as couriers and brought referrals from the primary healthcare. The important retrieval of patient medical history ${ }^{7}$ may have been hindered by three factors: (1) patients were not required to consult their general practitioner before the ER visit, leading to few referrals in acute situations, (2) patients limited their oral information when their providers asked few questions, and (3) hospital personnel often lacked access to patients' primary care electronic medical records. By the time of discharge, patients both functioned as couriers and received instructions from healthcare providers.

The recommendation for patient involvement in discharge planning was not followed by the participants in our study, with this potentially due to quick turnover in the emergency ward and a lack of time for healthcare providers to provide patients with sufficient information and ensure they understood their role. On the other hand, short patient stays do not justify the lack of formal discharge encounters. Patients need to fully understand the discharge process, yet may find it difficult to initiate communication with the healthcare providers when the time for communication is limited and in suboptimal locations. ${ }^{30}$

'Patient participation' in their health care has received increased international attention during the past decades, ${ }^{31} 32$ yet the concept lacks a clear and common definition ${ }^{33}$ in particular from the patient's point of view. ${ }^{35}$ Some patient activities reported in our study, such as patients assuming the responsibility for providing handover information to the next clinical microsystem, may be interpreted as a responsibility rather than participation. The ability to participate is known to be affected by the patient's cognitive abilities and functioning, ${ }^{28}$ and by their health condition. ${ }^{23}$ For patients with severe health problems, such a responsibility might be too much to ask, and at the end of a brief hospital stays, such as in the present study, it might be difficult for healthcare providers to assess patients' capacity for and interest in taking on this responsibility.

Our study found that some patients based their participation in the handover process on false assumptions, others lacked empowerment in the admission process and some lacked the trusting relationships to enable them to give and receive information. Discharge encounters may be an important enabler for patient participation in settings of short hospital stays and limited time for establishing a trusting relationship between patients and providers. Limitations of this study include its sample of chronically ill patients hospitalised due to acute conditions which may limit the ability to transfer findings to other patient group and settings. Most interviews were conducted several weeks after discharge, yet some patients still lacked a medical follow-up with their primary healthcare centre. Finally, patients were recruited by and interviewed at the hospital which may have produced a more favourable view of the hospital versus the primary care microsystem.

\section{CONCLUSIONS}

Patients with chronic diseases participated in handovers by sharing and conveying information. Patient participation decreased when patients believed their contribution did not add value to healthcare providers or to their care. Patients participate more actively when they perceive that they can, or must, to ensure their continuity of care. When patients assume responsibility to varying degrees, and the system does not adjust to these variations in participation, patient participation paradoxically may reduce patient safety.

Our study has implications for improving handover practice by increasing patient participation, while being 
sensitive to patients' knowledge, understanding and capacity for active engagement. The study also highlights the enabling factors that can be created by healthcare providers and the clinical microsystem. Patients need basic information about how clinical handovers work between the different microsystems involved in their care, and what is expected of them to help ensure high quality handovers. Patients also need to be made aware they can improve their handovers by being more actively involved, and healthcare providers need more knowledge on how to best enable patient participation in the handover. A redundant handover system that can effectively adjust to variation in patients' ability, resources and preferences for active participation in the handover may be the optimal solution to enhance patient safety. Healthcare provider training needs to consider these findings on this dynamic nature of patients' participation in handovers, and on the factors that contribute to trust and patient empowerment in this healthcare context.

Acknowledgements We would like to thank all participating patients for sharing their valuable experiences. Many thanks go to Fanny Airosa, who conducted half of the interviews and Susanne Bergenbrant Glas for important help and support. We would especially like to thank the European HANDOVER Research Collaborative: Venneri F, Albolino S, Molisso A, Toccafondi G (Azienda Sanitaria Firenze, Florence, Italy), Gademan P, Göbel B, Johnson J, Kalkman C, Pijnenborg L (Patient Safety Center, University Medical Center Utrecht, Utrecht, The Netherlands), Wollersheim W, Hesselink G,

Schoonhoven L, Vernooij-Dassen M, Zegers M (Scientific Institute for Quality of Healthcare, Radboud University Nijmegen Medical Centre, Nijmegen, The Netherlands), Boshuizen E, Drachsler H, Kicken W, van der Klink M, Stoyanov S (Centre for Learning Sciences and Technologies, Open University, Heerlen, the Netherlands), Kutryba B, Dudzik-Urbaniak E, Kalinowski M, Kutaj-Wasikowska H (National Centre for Quality Assessment, Krakow, Poland), Suñol R, Groene 0, Orrego C (Avedis Donabedian Institute, Universidad Autónoma de Barcelona, Barcelona, Spain), Lilford R, Chen Y-F, Novielli N, Manaseki-Holland S (University of Birmingham, Birmingham, UK).

Contributors MF was responsible for the data collection and data analysis, drafted and revised the paper. GÖ monitored the data collection, and revised the draft paper. HH monitored data collection and revised the draft paper. PB initiated, designed and was responsible for the HANDOVER-study and revised the draft paper. MO monitored data collection, analysed data and revised the draft paper. All authors were involved in the design of the study and the interpretation of the data.

Funding This study was supported by a grant from the European Union, the Framework Programme of the European Commission (FP7-HEALTH-F2-2008223409). The study sponsor had no role in the study design; collection, analysis, and interpretation of the data; or in the writing of the article and decision to submit the article for publication.

Competing interests None.

Provenance and peer review Not commissioned; externally peer reviewed.

Ethics approval The regional ethical review board in Stockholm, Sweden (No. 2008/1933-31/2).

Data sharing statement Data are available on request from the corresponding author.

\section{REFERENCES}

1. Barach $P$, Johnson JK. Understanding the complexity of redesigning care around the clinical microsystem. Qual Saf Health Care 2006;15: 110-16.
2. Forster AJ, Murff HJ, Peterson JF, et al. The incidence and severity of adverse events affecting patients after discharge from the hospital. Ann Intern Med 2003;138:161-7.

3. Hansagi $H$, Olsson $M$, Hussain $A$, et al. Is information sharing between the emergency department and primary care useful to the care of frequent emergency department users? Eur J Emerg Med 2008;15:34-9.

4. Maniaci MJ, Heckman MG, Dawson NL. Functional health literacy and understanding of medications at discharge. Mayo Clin Proc 2008;83:554-8.

5. Woolf SH, Kuzel AJ, Dovey SM, et al. A string of mistakes: the importance of cascade analysis in describing, counting, and preventing medical errors. Ann Fam Med 2004;2:317-26.

6. Moore C, Wisnivesky J, Williams S, et al. Medical errors related to discontinuity of care from an inpatient to an outpatient setting. J Gen Intern Med 2003;18:646-51.

7. Gleason KM, McDaniel MR, Feinglass J, et al. Results of the Medications at Transitions and Clinical Handoffs (MATCH) study: an analysis of medication reconciliation errors and risk factors at hospital admission. J Gen Intern Med 2010;25:441-7.

8. Tam VC, Knowles SR, Cornish PL, et al. Frequency, type and clinical importance of medication history errors at admission to hospital: a systematic review. Can Med Assoc J 2005;173:510-15

9. Carroll $\tilde{A}$, Dowling M. Discharge planning: communication, education and patient participation. Br J Nurs 2007;16:882-6.

10. Halasyamani L, Kripalani S, Coleman E, et al. Transition of care for hospitalized elderly patients-Development of a discharge checklist for hospitalists. J Hosp Med 2006;1:354-60.

11. Kripalani S, LeFevre F, Phillips CO, et al. Deficits in communication and information transfer between hospital-based and primary care physicians-Implications for patient safety and continuity of care. JAMA 2007;297:831-41.

12. Coleman EA, Parry C, Chalmers S, et al. The care transitions intervention-results of a randomized controlled trial. Arch Intern Med 2006;166:1822-8.

13. Jack BW, Chetty VK, Anthony D, et al. A reengineered hospital discharge program to decrease rehospitalization a randomized trial. Ann Intern Med 2009;150:178-88.

14. Meeuwesen L, van den Brink-Muinen A, Hofstede G. Can dimensions of national culture predict cross-national differences in medical communication? Patient Educ Couns 2009;75:58-66.

15. The HANDOVER Research Consortium project, FP7-HEALTH-F22008-223409, see http://www.handover.eu (2012-05-12).

16. The Act on System of Choice in the Public Sector (Lag om valfrihetssystem), in SFS 2008:962. 2008.

17. Act on Patient Safety (Patientsäkerhetslagen), in SFS 2010:659. 2011.

18. The National board on health and welfare, Regulations on cooperation regarding admission and discharge of hospitalised patients (Socialstyrelsens föreskrifter om samverkan vid in- och utskrivning av patienter i sluten vård) in SOSFS 2005:27. 2005.

19. Tong A, Sainsbury P, Craig J. Consolidated criteria for reporting qualitative research (COREQ): a 32-item checklist for interviews and focus groups. Int J Qual Health Care 2007;19:349-57.

20. Hansagi $\mathrm{H}$, Olsson $\mathrm{M}$, Glas $\mathrm{S}$, et al. Report on the barriers and facilitators to effective handovers in the social, linguistic and technological context in which they take place. Utrecht, The Netherlands: Utrecht Medical Center, 2010.

21. ATLAS.ti Scientific Software Development Company, GmbH, Berlin, Germany. http://www.atlasti.com/ (2012-05-13).

22. Hsieh HF, Shannon SE. Three approaches to qualitative content analysis. Qual Health Res 2005;15:1277-88.

23. Davis RE, Jacklin R, Sevdalis N, et al. Patient involvement in patient safety: what factors influence patient participation and engagement? Health Expect 2007;10:259-67.

24. Frank C, Asp M, Dahlberg K. Patient participation in emergency care -a phenomenographic study based on patients' lived experience. Int Emerg Nurs 2009;17:15-22.

25. Larsson IE, Sahlsten MJM, Sjostrom B, et al. Patient participation in nursing care from a patient perspective: a Grounded Theory study. Scand J Caring Sci 2007;21:313-20.

26. Ventres W, Kooienga S, Vuckovic N, et al. Physicians, patients, and the electronic health record: An ethnographic analysis. Ann Fam Med 2006;4:124-31.

27. Efraimsson E, Sandman PO, Hydén L, et al. Discharge planning: 'fooling ourselves?'-patient participation in conferences. J Clin Nurs 2004;13:562-70.

28. Rydeman I, Tornkvist $L$. The patient's vulnerability, dependence and exposed situation in the discharge process: experiences of district 
nurses, geriatric nurses and social workers. J Clin Nurs 2006;15:1299-307.

29. Reinius $\mathrm{P}$, Johansson M, Fjellner A, et al. A telephone based case management intervention reduces health care utilisation for frequent emergency department visitors. Eur J Emerg Med. 2012 Sep 6. [Epub ahead of print]

30. Almborg A, Ulander K, Thulin A, et al. Patients' perceptions of their participation in discharge planning after acute stroke. J Clin Nurs 2009;18:199-209.

31. World Health Organisation. A declaration on the promotion of patients' rights in Europe. WHO, Regional Office for Europe Copenhagen, Denmark. 1994.
32. Virone MG, Tarasenko N. Patient safety \& rights: developing tools to support consumer health literacy. WHO, Regional Office for Europe Copenhagen, Denmark. 2010.

33. Longtin Y, Sax H, Leape LL, et al. Patient Participation: Current Knowledge and Applicability to Patient Safety. Mayo Clin Proc 2010;85:53-62.

34. Sahlsten MJM, Larsson IE, Sjostrom B, et al. An analysis of the concept of patient participation. Nurs Forum 2008;43:2-11.

35. Eldh AC, Ekman I, Ehnfors M. A comparison of the concept of patient participation and patients' descriptions as related to healthcare definitions. Int J Nurs Terminol Classif 2010; 21:21-32. 